http://dx.doi.org/10.5007/2175-7984.2012v11n20p11

\title{
Apresentação: Um conjunto apenas aparentemente heterogêneo de contribuições
}

\section{Alberto Cupani ${ }^{1}$ Julia S. Guivant ${ }^{2}$ Pierre Delvenne ${ }^{3}$}

\begin{abstract}
iniciativa de organizar este dossiê surgiu a partir de atividades que compartilham os organizadores como membros do convênio Capes/Wallonie Bruxelles International ${ }^{4}$. Durante a vigência do convênio (2011-2013), pretendemos estudar os desafios para a ciência moderna e os regimes de inovação quando as instituições existentes não são suficientes para gerir eficazmente os problemas levantados pela globalização, o impacto ambiental e social da tecnologia, a demanda para o envolvimento com o público, da competitividade e da propriedade intelectual. Pretendemos nos concentrar na identificação desses desafios e respostas tomando os casos da Bélgica (para o contexto europeu) e do Brasil (para o contexto latino-americano) e avaliar as diferenças e semelhanças entre os desafios enfrentados pela governança de ciência, tecnologia e inovação (CTI).
\end{abstract}

1 Professor titular do Departamento de Filosofia da Universidade Federal de Santa Catarina (UFSC), integrante do grupo de pesquisa Lógica e Fundamentos da Ciência.

2 Professora do Departamento de Sociologia e Ciência Política da Universidade Federal de Santa Catarina (UFSC), coordenadora do Instituto de Pesquisa em Risco e Sustentabilidade (IRIS), membro do comitê diretor da Society for the Study of Nanoscience and Emerging Technologies (S.Net). juliaguivant@gmail.com.

3 Pierre Delvenne supervisiona o polo Science, Technologie et Sociéte (STS) no Instituto de Pesquisa Spiral, do Departamento de Ciência Política da Universidade de Liège, Bélgica. É pesquisador do Fonds de la Recherche Scientifique (FNRS). pierre.delvenne@ ulg.ac.be.

4 Projeto 003/10, coordenado por Julia S. Guivant (IRIS, UFSC, Brasil) e Sébastien Brunet (Spiral, Universidade de Liège, Bélgica). 


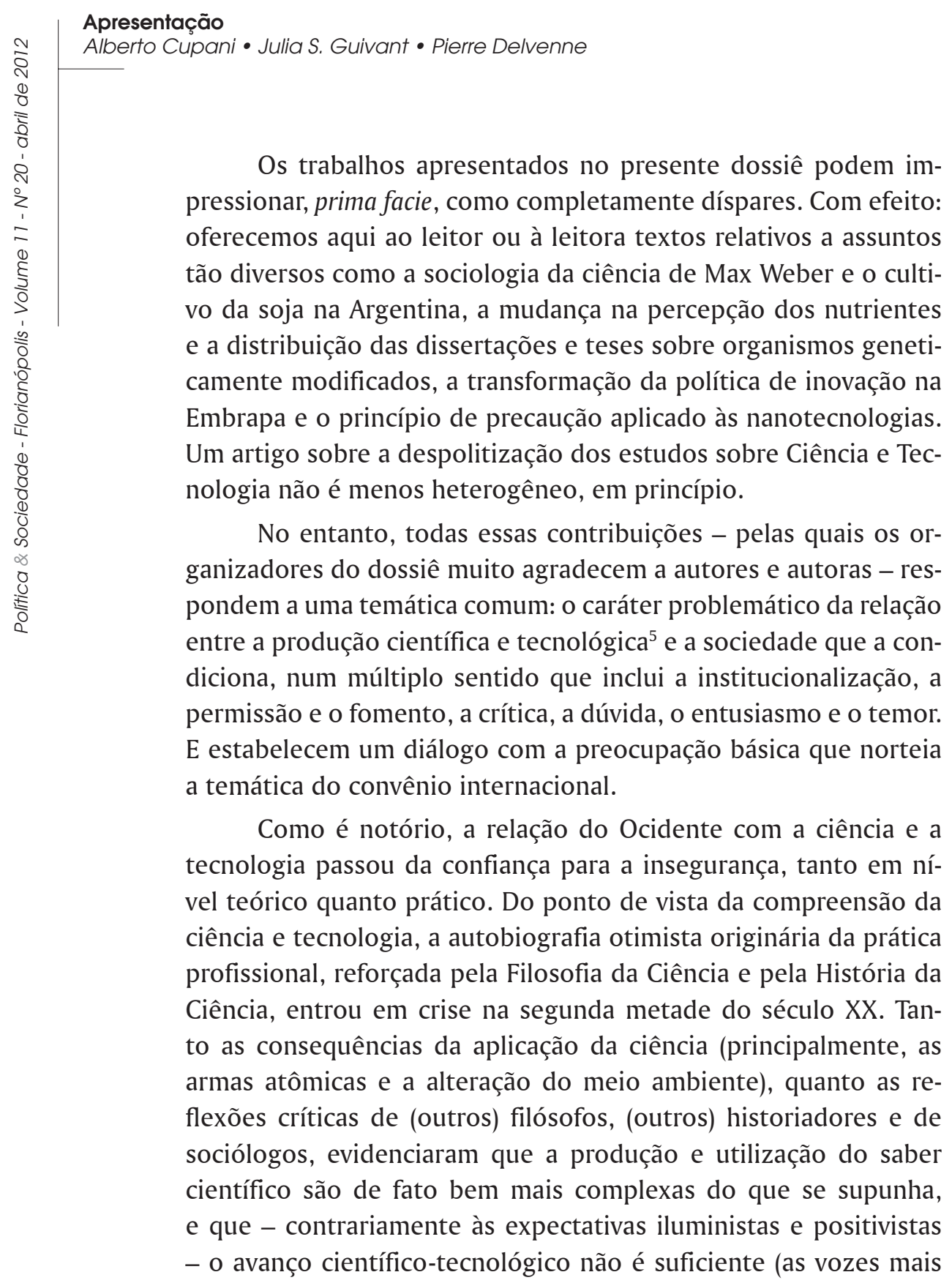

5 Preferimos nesta introdução a expressão "tecnologia", consagrada para distinguir as técnicas e sistemas produzidos com intervenção da pesquisa científica, ou dela decorrentes, à diferença da produção técnica vinculada à experiência e ao saber ordinários. Por outra parte, os trabalhos reunidos no dossiê recorrem a essa expressão. 
críticas suspeitam que nem é necessário) para que a humanidade consiga viver melhor.

A dúvida e o questionamento da ciência e da tecnologia abrangem diversos assuntos, a começar pela própria identificação do conhecimento científico como um entendimento objetivo da realidade, natural e social. Esse entendimento parecia repousar na nítida distinção entre fatos e valores, sendo os primeiros ocorrências estabelecidas de modo razoavelmente seguro e explicadas pela pesquisa científica de maneira neutra no que tange a julgá-las. O âmbito dos juízos, dependente dos valores (morais, religiosos, econômicos, estéticos) estava excluído da ciência, que, no entanto, podia ser colocada a serviço daqueles valores que um indivíduo (caso da vocação do cientista) ou uma comunidade (com desejo de "progredir") escolhesse. Essa separação entre fatos e valores mostrou-se ilusória, não apenas na prática, mas também na análise epistemológica do conhecimento científico.

A uma Filosofia da Ciência mais atenta à atividade científica efetiva resultou claro que, além dos critérios epistemológicos que caracterizam a geração de um saber confiável, os cientistas se veem obrigados amiúde a apelar para critérios de outra índole devido à incerteza que acompanha toda comprovação e toda previsão científicas. Os pesquisadores devem julgar (individual e coletivamente) se, e em que medida, o saber produzido é confiável. Isso implica em reconhecer diferenças, até dentro da mesma especialidade, em modos de caracterizar os problemas, na confiança em determinadas metodologias, e na preferência por certo tipo de hipóteses ou teorias. E a consequência dessas diferenças é a necessidade de "negociarem" conclusões que pareçam razoáveis. O juízo e a negociação devem, em tese, atentar não apenas para as decorrências teóricas das opções escolhidas, mas também para as decorrências práticas (sejam elas de caráter social, econômico, político ou moral). Estamos longe da crença em que a ciência exclui valorações. Também, de que a pesquisa possa controlar totalmente os efeitos das suas aplicações. Como resultado dessas incertezas, vivemos numa sociedade de risco onipresente, inevitável (BECK, 2010). 


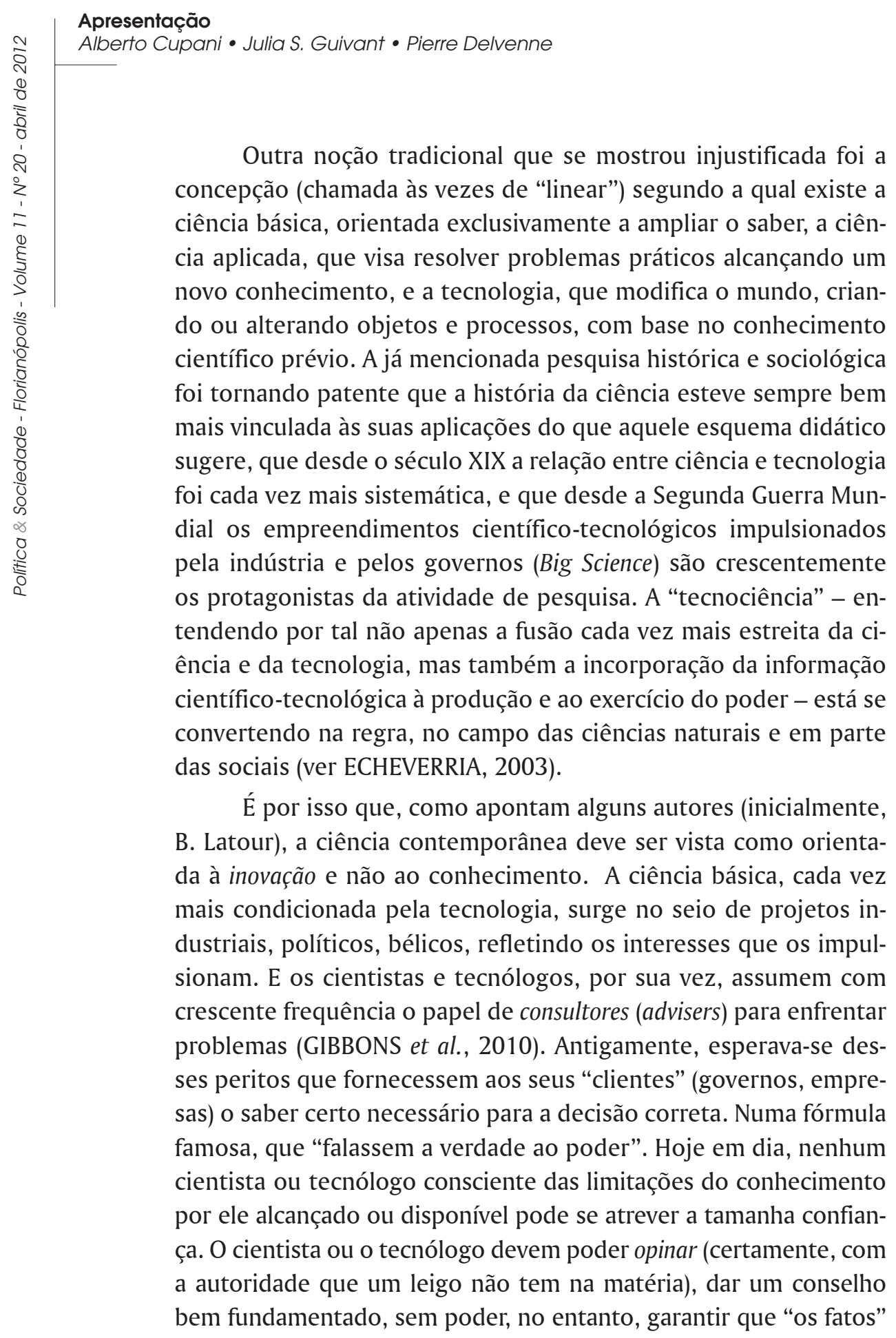


são necessariamente assim, nem que as previsões resultarão tal como calculado. A existência de diversos cientistas ou tecnólogos a quem pedir sua opinião, longe de facilitar um juízo seguro, o complica, pelas razões antes mencionadas. Tanto quanto a certeza do diagnóstico, perdeu-se a confiança na unicidade da decisão correta.

A crise de confiança na ciência e na tecnologia trouxe consigo o questionamento daquelas atividades como as fornecedoras da única ou da melhor maneira de compreender a realidade e de agir. Os saberes vulgares, que permitiram a sobrevivência do ser humano e de suas diversas culturas durante milênios, foram reivindicados, após terem sido considerados, durante duzentos anos, como formas de conhecimento e de operação destinadas a serem substituídas pela ciência e pela tecnologia. A desilusão com relação aos peritos, já não mais indicadores infalíveis da verdade e da correção, alimenta a pressão para que os problemas sejam examinados por equipes que incluam, junto aos experts científicos e tecnológicos, leigos interessados e/ou afetados pelas decisões a serem tomadas. Mais ainda: algumas vozes propõem que a confiabilidade do saber científico tecnológico não seja matéria de decisão puramente inter pares, mas que inclua a apreciação dos leigos (numa disciplina) que podem ser, a seu modo, peritos (na vivência do problema a ser resolvido). ${ }^{6}$

$\mathrm{O}$ anterior significa também que se questiona atualmente a confiança em que a ciência e a tecnologia sejam o instrumento por excelência para governar (o ideal tecnocrático). Na conhecida expressão de Ullrich Beck, "a ciência não pode ser a solução, pois é parte do problema" (o que vale, obviamente, também para a tecnologia). Não é sem razão que a questão da "governança" é cada vez mais frequente na pesquisa, na análise e na discussão social - incluída, é claro, a governança do próprio sistema científico-tecnológico. Nas discussões específicas, a propósito de tal ou qual projeto científico-tecnológico, isso equivale a aceitar que,

6 A esta convição responde a proposta de um conhecimento "socialmente robusto" (NOWOTNY et al., 2010). 


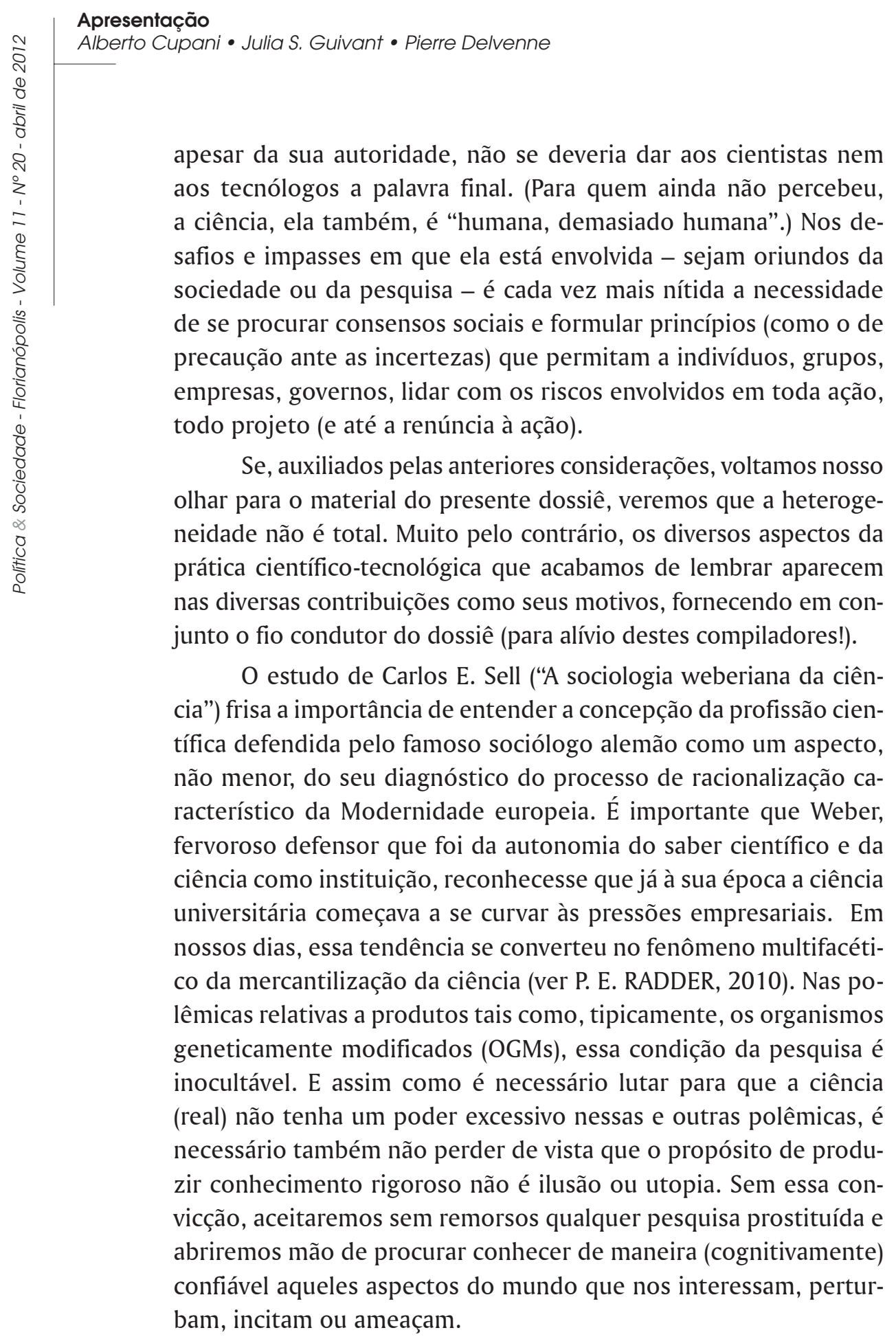


Marília Luz David e Julia S. Guivant ("A gordura trans: entre as controvérsias científicas e as estratégias da indústria alimentar") analisam a transformação da percepção do papel dos nutrientes, tomando o caso das gorduras trans. Estas últimas foram, durante longo tempo, consideradas a alternativa saudável para as gorduras animais, até se verificar, não sem discussões e ambiguidades, que as gorduras trans não são tão inofensivas quanto se pensava, particularmente com relação à regulação do colesterol no organismo. As autoras fazem a história deste "processo de mudança da gordura trans de panaceia para vilã, e como foram se posicionando neste processo importantes atores institucionais e econômicos, como os cientistas e as empresas alimentares". Merecem destaque as observações sobre as estratégias defensivas da indústria até sua capitulação ante os consensos científicos e as decisões dos órgãos reguladores, a fragilidade e limitação das perícias que operam dentro do sistema alimentar, e a ambiguidade da situação atual (margens permitidas à indústria e informação insuficiente ao consumidor).

O trabalho de Thales Novaes de Andrade ("A avaliação de impactos ambientais: redefinindo a inovação tecnológica") aborda, mediante um estudo de caso, a relação da pesquisa científico-tecnológica com a sociedade, focalizando em particular a circunstância de que a inovação tecnológica exige amiúde inovação institucional. $\mathrm{O}$ autor apresenta a mudança de política institucional da Embrapa em função da crescente necessidade de se atender aos impactos ambientais. Também, a mudança consistente em passar de uma política de "oferta" a outra de "pesquisa por demanda". É particularmente importante a declaração do autor de que "não é mais possível financiar projetos tecnológicos e de inovação sem incorporar metodologias de avaliação que estabeleçam parâmetros de desempenho e eficácia dos projetos”. Essa eficácia não deve, todavia, se reduzir "à sua funcionalidade restrita", mas incluir os impactos (no caso, ambientais). Em matéria de avaliação, aparece aqui o reconhecimento da necessidade de ampliar o âmbito de agentes que avaliam políticas e impactos, para além do círculo dos profissionais. Também: a necessidade de ir além de avaliações puramente 


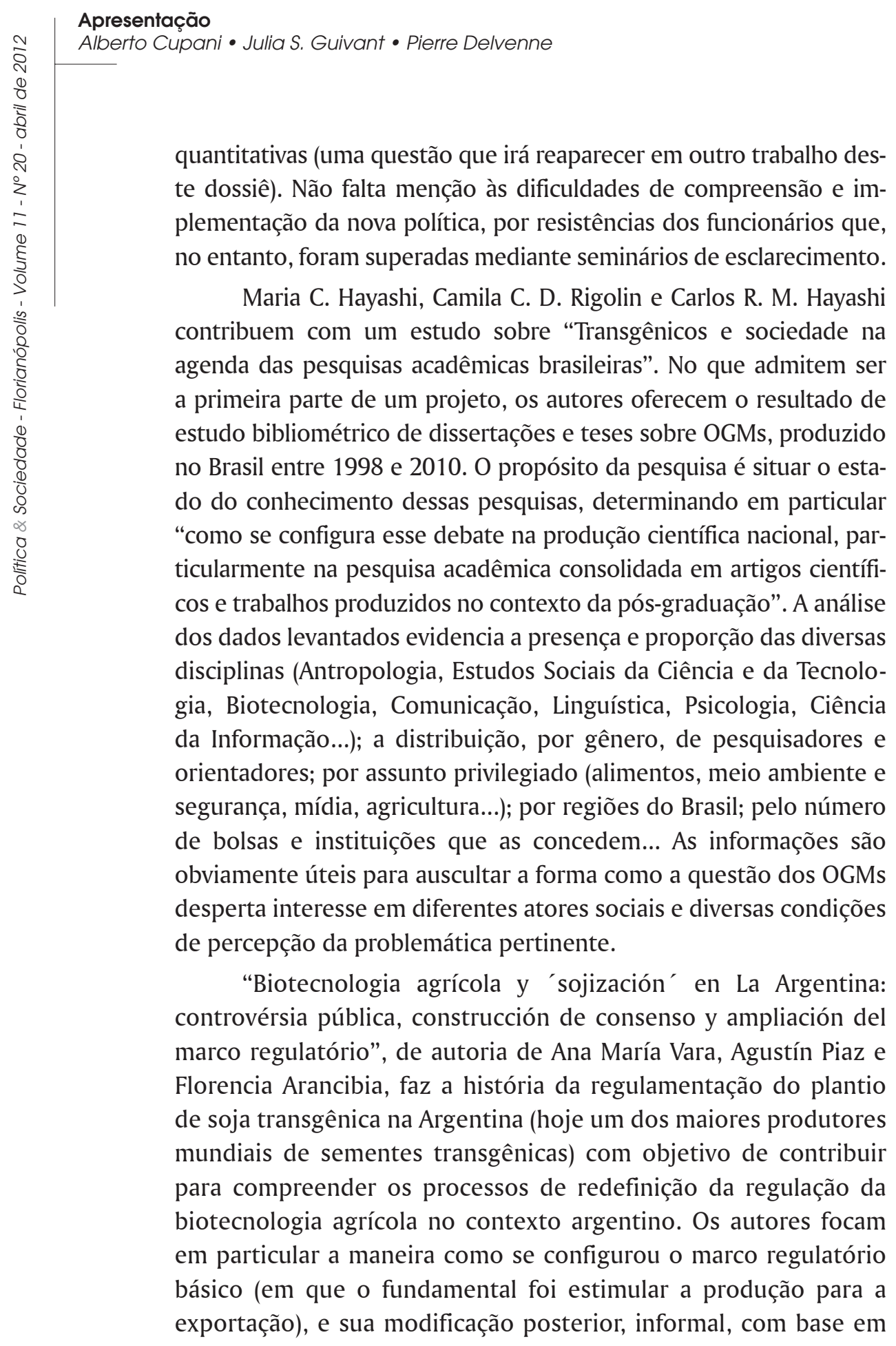


resistências vinculadas a três questões: o impacto alimentar dos OGMs, o problema da agriculturização prejudicial ao meio ambiente e o uso de agroquímicos. Baseando-se em entrevistas com representantes de ambas as posições (pró e contra os transgênicos), e de variada posição social (industriais, técnicos, políticos...), o estudo mostra que o consenso ("inestável") inclui reconhecimento parcial, pelos atores enfrentados, dos pontos positivos da parte contrária e de que a questão dos transgênicos faz parte de problemas mais abrangentes que incluem, p.e., a questão dos biocombustíveis e a relativa à "estrangeirização".

A relação entre o risco e a incerteza, a que aludimos, é central em "Tratando as nanopartículas com precaução: reconhecendo a incerteza qualitativa na avaliação científica do risco", de Fern Wickson, Frodys Gillund e Anne I. Myhr Genok. Os autores partem de lembrar que, na estimação de riscos, a noção tradicional de ciência objetiva, isenta de valores, capaz de dar contribuições objetivas e calcular com certeza possibilidades, está ultrapassada. No entanto, observam, a estimação de riscos continua a ser feita em base a considerações quantitativas, o que é particularmente defeituoso em matéria de tecnologias emergentes, como as vinculadas a nanopartículas. Após apresentarem uma importante classificação dos tipos de incerteza (para os quais escolhem a denominação genérica de incertitude) os autores enfatizam a importância de riscos "mais qualitativos" (indeterminação, ignorância e ambiguidade) e propõem uma forma de lidar com tais riscos. Discutem a seguir o princípio de precaução sugerindo a conveniência de transformá-lo em um enfoque (e não uma regra). $O$ trabalho inclui considerações acerca dos tipos de pesquisas que a incerteza exige, bem como da necessidade de tornar transparentes os processos de estimação de riscos, em virtude da dificuldade de separar fatos e valores. Outras necessidades incontornáveis seriam as de levar em consideração múltiplas possibilidades de definir problemas e escolher metodologias de análise, de negociar conclusões e - não menos importante - de incluir outros saberes além do científico.

Também relativo às nanopartículas, porém desde uma perspectiva diferente, é o artigo "Have STS fallen into a political void? 


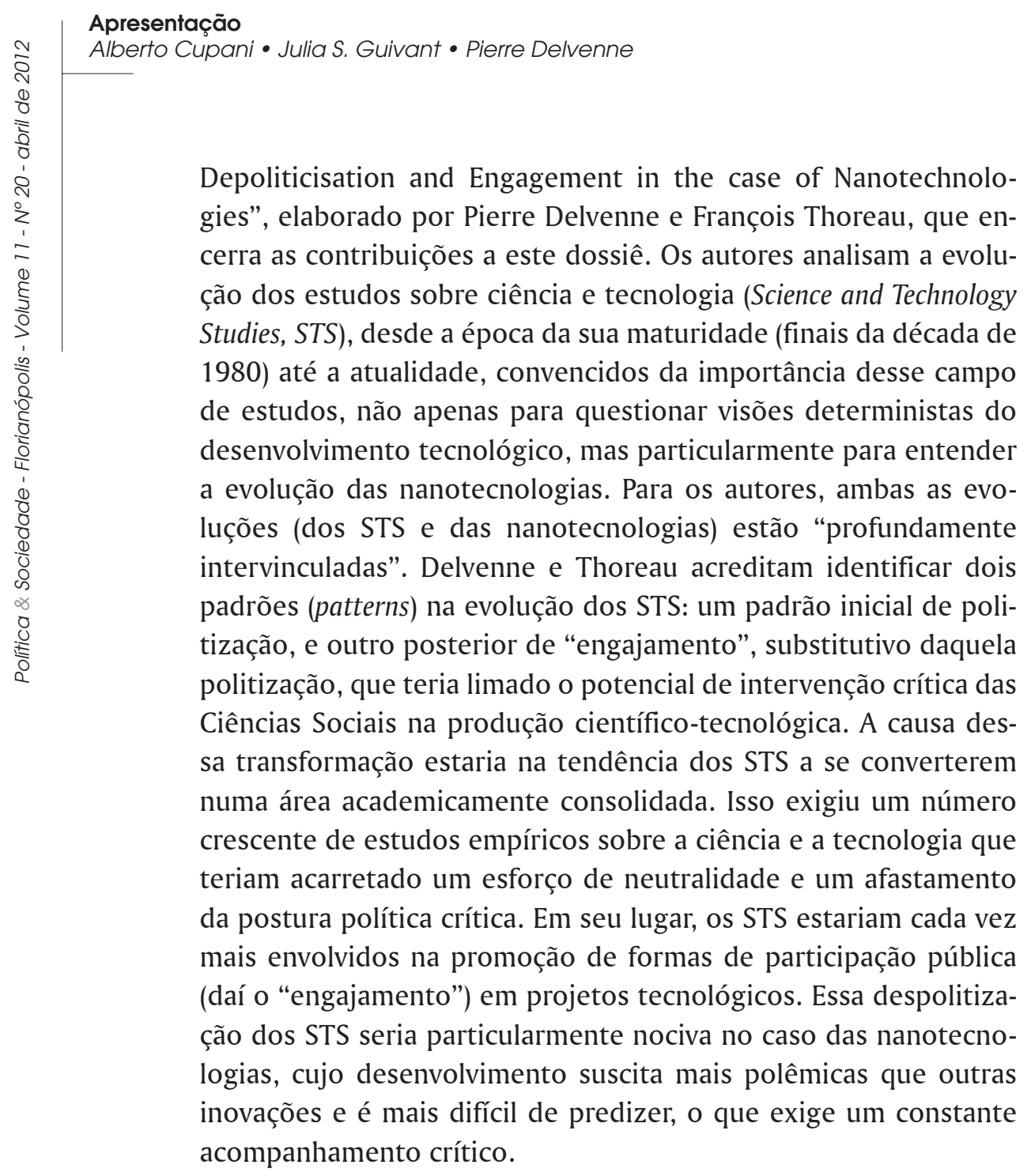

\section{Referências}

BECK, U. Sociedade de risco: rumo a uma outra modernidade (Rissikogesellschaft: auf them Weg in eine andere Moderne, 1986). São Paulo: 34. ed. 2010.

ECHEVERRÍA, J. La revolución tecnológica. Madrid: Fondo de Cultura Económica de España. 2003. 
GIBBONS, M., LImoges, C., Nowotny, H., Schwartzman, S., Scott, P. e Trow, M. 2010 [1994] The new Production of knowledge: the dynamics of science and research in contemporary societies. Los Angeles/London: Sage.

NOWOTNY, H.; SCOTT, P. e GIBBONS, M. 2010 [2002] Re-Thinking Sience: knowledge and the public in an age of uncertainty. Cambridge, UK/ Malden, USA: Polity.

RADDER, H. (comp.) The commodification of academic research: science and the modern university. Pittsburgh: Univ. of Pittsburgh Press. 2010. 